\title{
SINGULARIDADES E DIFICULDADES DO PENSAMENTO DE HANS JONAS
}

\author{
Lourenço Zancanaro \\ Universidade Estadual de Londrina
}

\begin{abstract}
Hans Jonas appears as one of the most important philosophers of the twentieth century, but still not much studied. His research about philosophy of technology aimed to present an ethical reflection about the possible consequences in relation to its use. The theory of liability arises in an environment of ethical crisis facing the new demands of the act caused by technology especially in the ecology field and the progress of life science especially in biology. Now the man passed from subject of the research to the object of it. This paper will present some problems of reasoning in the ethics of responsibility, regarding the central theme, which is the ontological foundation. This is the biggest problem of Jonas thought: How to sustain the ontological argument using the pre-moderns, something that is denied in modern philosophical meditation?
\end{abstract}

Keywords: Ethic, responsibility, technology, ontological.

Resumo: Hans Jonas aparece como um dos filósofos mais importantes do século XX, mas ainda muito pouco estudado. Sua investigação sobre a filosofia da tecnologia teve como objetivo apresentar uma reflexão ética acerca das possíveis conseqüências em relação ao seu uso. A teoria da responsabilidade surge num ambiente de crise da ética diante das novas exigências do agir provocadas pela tecnologia especialmente no campo da ecologia e dos avanços das ciências da vida especialmente da biologia. Agora o homem de sujeito de pesquisa passou a ser objeto. O presente trabalho apresentará alguns problemas de fundamentação da ética da responsabilidade, no que se refere ao tema central, que é a fundamentação ontológica. Este é o maior problema do pensamento de Jonas: Como sustentar o argumento ontológico recorrendo aos pré-modernos, algo que é negado na meditação filosófica moderna?

Palavras-chave: Ética, responsabilidade, tecnologia, ontologia. 


\section{Introdução}

"Age de tal forma que os efeitos das ações não sejam capazes de colocar em risco a possibilidade de vida no futuro" (Hans Jonas).

O que mais desafia os estudiosos da ética de responsabilidade formulada por Hans Jonas, a partir dos anos 60 do século passado, é a questão da sua fundamentação. São inúmeras as críticas. Entre elas, por ter recorrido aos pré-modernos algo proibido para a filosofia contemporânea, fazer uso de categorias metafísicas, existencialistas e ontológicas para sua ética. Este estudo quer mostrar algumas críticas feitas ao seu pensamento no que concerne ao fundamento da ética, ao estatuto da ética da natureza, ao estatuto prescritivo ou somente proibitivo da responsabilidade e a sua articulação política. Obviamente, são inúmeras as avaliações positivas, especialmente a que defende que ele elaborou a teoria da responsabilidade para chamar atenção sobre o niilismo moderno, do vazio de valores que nos encontramos em face dos impactos da tecnologia sobre nosso agir. Nesse sentido afirma que a ética da responsabilidade é uma afirmação do imperativo da existência: "Age de tal forma que os efeitos das ações não sejam capazes de colocar em risco a possibilidade de vida no futuro”. É nesta direção que desenvolverei as singularidade e dificuldades do seu pensamento, apresentando as análises feitas por, Bernard Sève, Jean Greich, Gilbert Hottois, André Dumas, Richard Marienstras, Robert Spaemann e Paul Ricoeur.

Jonas deixa claro que a investigação sobre a essência do homem deve percorrer o caminho entre os encontros do homem com o ser. Nesses encontros ela não só vem à luz como em geral também se realiza, porque, em todo encontro, ela se descobre. Existe uma "continuidade entre mente e organismo, entre organismo e natureza e por isso a ética se torna parte da filosofia da natureza" (JONAS, 1991, p. 35).

Nesse sentido, a análise existencialista de Jonas está sintonizada com o verdadeiro sentido da palavra existência, como um modo de ser próprio do homem enquanto é um modo de ser no mundo, isto é, sempre em uma situação determinada, analisável em termos de possibilidade. Só compreendemos o sentido do ser analisando nossa "existência (pre-sença $=$ dasein) 
(HEIDEGGER, 1997, p. 33). A existência se constitui de escolhas concretas que, analisadas, deixam transparecer o sentido que nos liga ao ser antes de qualquer discussão teórica.

É nessa perspectiva que Jonas analisa a gnose como uma situação específica, um modo determinado de conceber o mundo e a vida, não em termos de consciência, espírito ou interiorização. Existir significa estar em relação com o mundo, isto é, com as coisas e com os outros homens em termos de possibilidades.

A compreensão da existência do ser conota um movimento de transcendência. Isto significa que o fim para o qual o homem se destina está no mundo. A transcendência pode ser definida como "estar-no-mundo". Qual o sentido do mundo? É um sentido referencial porque ele contém o que determina no homem o desejo à transcendência. Isto significa que o mundo é projeto das possíveis atitudes e ações do homem. O mundo feito pelo homem compreende o homem e o submete às suas limitações. Logo, por ser um ato de escolha, o mundo representa a própria liberdade que, dependendo da utilização do poder, pode colocar em perigo a existência que clama existir.

A análise do niilismo moderno, ou seja, do modo de existir do homem moderno, mostra características próprias em termos de alienação do homem nas promessas baconianas e prometeanas da utopia tecnológica. $\mathrm{O}$ "modo de ser" (GREICH, 1991, p. 8) do homem moderno pode ser analisado em termos de possibilidades ou conseqüências que podem fugir ao controle. Por isso, o existencialismo afirma que o homem é uma realidade finita. Existe e opera com seu próprio risco e perigo. É diferente do romantismo que acredita plenamente no êxito, na ação de uma força infinita da qual o homem é somente manifestação.

O entendimento da ética de responsabilidade tal qual nos é proposta por Jonas torna-se incompreensível sem a análise das categorias existenciais heideggerianas. Como seu aluno na década de 20, incorporou as categorias descritivas fundamentais do existencialismo visto que estão voltadas para o futuro. A influência pode ser notada pelo uso das estruturas existenciais, como: possibilidade, projeto, renúncia, presente, passado, futuro, liberdade, cuidado, temor, e existência. Também os estudos históricos sobre a gnose dos primeiros séculos do cristianismo fizeram-no despertar para a análise de tecnologia moderna. Se na antigüidade havia uma alienação em Deus, hoje 
ela está direcionada à técnica, e se revela como "niilismo". Como uma supervalorização dos entes em detrimento do ser

Em Jonas, a antecipação do futuro está na possibilidade de não mais existir, tornando o presente cenário de preocupações, que garante pouco, porque o futuro está fora do presente. A compulsão desenfreada na conquista, não medindo as conseqüências, revela a falta de cuidado com o presente. O futuro se revela como um contínuo inesperado que é necessário zelar, comprometendo o homem com o presente. Tal significado assegura que responsabilidade é preocupar-se com o futuro. Aqui se revela novamente a heurística do temor, ou seja, sem o pressentimento do futuro, o presente seria uma terra sem cuidados. Assim, a idéia heideggeriana de "pastor do ser" (HEIDEGGER, 1979, p. 163) adquire uma dimensão pedagógica em Jonas, cujo sentido envolve tudo o que é susceptível de transformação pelo poder do homem. Para que essa possibilidade se mantenha viva é necessária uma ética de preservação, de previsão, de custódia, de renúncia, expressa como um incisivo "não ao não ser" e uma "prioridade do dever da existência" (JONAS, 2006, p. 92).

Tanto para Heidegger, como para Jonas, o salto para uma nova sociedade está em superar a equivocada concepção tecnológica prevalente do ser. São dominados por uma angústia em solucionar os problemas da humanidade. Em Jonas é uma urgência quase apocalíptica e, em Heidegger, um apelo quase desesperado e dominado pela descrença na possibilidade de encontrar uma saída para a técnica. Em Heidegger, temos a angústia e, em Jonas, a heurística do temor, como substituta das projeções anteriores de esperança, nas promessas de redenção utópica da moderna tecnologia. Desta forma entende-se a necessidade do resgate da idéia heideggeriana de "pastor do ser”.

Compartilhamos das suas ambições na busca de novos princípios para a ética num mundo onde os exageros tecnológicos e seu excesso de poder provocaram mudanças no agir. Sua incursão no campo da ética parte da evidência e da obviedade de fatos concretos. Constata Jonas que, à medida que houve mudanças no agir, e já que a ética trata dos costumes, são necessárias mudanças no seu estatuto para que possa adequar-se aos novos tempos. Tal argumentação evidencia que os imperativos da ética tradicional são insuficientes para limitar a ação e o poder onipotente da tecnologia, que objetiva submeter tudo ao seu domínio. 
Diante dos enormes progressos da tecnologia, os conceitos de honestidade e de fraternidade, embora continuem válidos, não possuem a mesma força de transformação nem a mesma capacidade de impor limites aos ilimitados poderes da ciência, aliada aos interesses ideológicos de nações e à exacerbação do individualismo e do agir coletivo. Esta constatação induzirá à necessidade de novos princípios em vista do desconhecimento das possíveis conseqüências desta cadeia causal.

Uma análise do conceito de responsabilidade de Jonas não pode deixar de ressaltar a ousadia do novo plano, que trouxe para a reflexão ética conceitos até hoje ausentes na atividade filosófica. Não poderemos também deixar de apontar algumas dificuldades do seu empreendimento. Iniciamos com a posição de Bernard Sève que indica sua grandiosidade, porém não se eximindo de apontar as dificuldades. "As ambigüidades deste livro são a medida de sua riqueza e de suas ambições" sintetizando as críticas em quatro pontos. A primeira se refere ao "fundamento da ética"; a segunda, ao "estatuto da ética da natureza"; a terceira ao "estatuto prescritivo ou somente proibitivo da responsabilidade”; a quarta, à "sua articulação com a política”. (SÈVE, 1991, p. 82).

Como sabemos, Jonas foi marcado por uma forte influência do pensamento de Heidegger, da fenomenologia de Husserl, dos estudos históricos com Bultmann, além de pertencer ao círculo intelectual de Hannah Arendt, Karl Jaspers, entre outros. Sua experiência com o holocausto provocou mudanças muito grandes na compreensão da existência diante do progresso científico e tecnológico.

Para Seve (1991) o primeiro problema está ligado à questão do "fundamento" e do debate com Kant. Jonas acredita poder fundar o imperativo ético no "ser", partindo de uma argumentação metafísica da qual o kantismo exclui a possibilidade. A crítica de Jonas a Kant refere-se ao imperativo formalista e individualista, coerente na sua forma lógica e no âmbito do agir próximo. Entende que o formalismo "não permite pensar a responsabilidade ilimitada com o futuro" e, por isso, "não poderia fundar seu imperativo categórico formal”, porque o agir tecnológico é coletivo e a cadeia de ações individuais teria pouco poder de transformação.

Para Sève, a leitura que Jonas faz de Kant é contestável, embora não queira dar a ele uma lição de kantismo. Arremata que esse problema mereceria um estudo especial. Refere-se à explanação do conceito de responsabilidade como um "conceito forte, original e indispensável e não 
pretende contestar sua novidade nem sua força”, (SÈVE apud HOTTOIS, 1993, p. 109) embora segundo sua visão, a polêmica que Jonas levanta "obscurece um pouco as coisas". Se Jonas sustenta que seus imperativos não têm auto contradição, para Seve esse raciocínio anti-kantiano não pode ser admitido. (SÈVE, 1990, p. 82).

Jonas finge cometer o erro segundo o qual a imoralidade para Kant se refere à contradição lógica; se fosse assim, a vontade não poderia ser sempre imoral. Em termos kantianos: a idéia de que um dia a humanidade possa deixar de existir não contém nenhuma contradição lógica; mas a vontade plena e inteira que se produzisse (ou que se deixasse de produzir) uma situação tal que a humanidade não possa existir é impossível, não podemos querer isso. Esta rejeição ao kantismo é indispensável ao projeto de Jonas, que quer estabelecer a necessidade de um fundamento ontológico da ética (do qual o kantismo exclui a possibilidade) (SÈVE, 1990, p. 82-3).

Ao citar “A fundamentação da metafísica dos costumes”, Seve (1990) afirma ser possível inferir um imperativo categórico da responsabilidade em direção à humanidade futura, citando "o mandamento do suicida; o dever de assistência” e, na terceira formulação kantiana do princípio categórico "(tratar a humanidade na pessoa do outro sempre como fim) cujo sentido é dar uma extensão temporal indefinida à noção de homem”, extensão que não poderá ser sonhada com Jonas, mas perfeitamente compatível com a letra do pensamento kantiano. Seve diz ser muito curiosa a insistência de Jonas sobre "porque é necessário que a humanidade exista" e, mais curioso ainda, que em nenhum momento faça alusão à "Crítica da Faculdade de Julgar" (parágrafo 82), muito rica nesse sentido.

Para Sève, Jonas não teve êxito nessa sua fundamentação. A dificuldade está em reconhecer ele próprio a metafísica e a objetividade dos valores e fins domiciliados na natureza, quando dá a entender que é somente “razoável e provável, mas não certo" (JONAS, 1984, p. 73-4). O que Jonas trata de fundar é um tanto ambíguo e "não está seguro de o compreender". Questiona o empreendimento de Jonas, perguntando:

É esta a obrigação incondicional de existir para a humanidade que é necessário fundar? Mas esta incondicionalidade está em 
ruptura com a existência de fato do homem: 'o mandamento ontológico' (...) institui a 'coisa no mundo' fundamental (...) que obriga doravante a humanidade, uma vez que é colocada a existir efetivamente, mesmo se é um destino cego que a tem feito aparecer; ( ...) a mesma página um pouco mais ao alto o mandamento ontológico não tem fundamento; e como fundar o imperativo na natureza se a existência é um destino? É esta a finalidade em geral (que é o bem em si) que é necessário fundar? Mas esta 'lei de auto justificação do fim no que respeita a tal' não é um axioma ontológico ofertado à intuição? É esta minha responsabilidade ilimitada em direção ao futuro? A propósito da responsabilidade que o recémnascido me impõe, Jonas fala da 'evidência imediata' por estes que queremos ter. Finalmente, o fundamento último se volta à natureza intuitivamente verdadeira do princípio da responsabilidade. Isto que eu temo, é um esforço pouco convincente para fundar metafisicamente $\mathrm{O}$ princípio responsabilidade não o enfraquece, de fato, no lugar de o reforçar (SÈVE, 1990, p.83).

Ao questionar a "obrigação incondicional de existir da humanidade", mostra que toda obrigação está "em ruptura com a existência de fato do homem". Para Jonas, é o "mandamento ontológico" que obriga, mesmo tratando-se do acaso. Para ele, o acaso é sempre uma fonte de renovação, pois assegura a surpresa, o nascimento do único, ao contrário da compulsão científica com sua dimensão utópica. Sève questiona se essa percepção de Jonas "não é um axioma ontológico ofertado à intuição". O mesmo vale para a responsabilidade paterna com o recém-nascido.

A segunda crítica se refere ao "estatuto da natureza". Jonas avalia que temos deveres para com ela (responsabilidade e respeito) e que para isso é necessário escapar ao antropocentrismo tradicional das morais anteriores. Seve (1990, p. 84) comenta:

Afirmar que a natureza deve ser respeitada é uma boa causa e tem grandes méritos como propaganda moral que eu não desprezo; antropomorfizar a natureza pode servir de uma boa retórica, para uma boa causa, como pode mover a consciência para que os poluidores reduzam a poluição, mas como tese filosófica é muito frágil. 
Para que se considere que o homem é responsável pelo homem e, indiretamente, pela natureza, para que possa bem viver, não é necessária nenhuma interpretação metafísica e, muito menos, teológica da natureza. Para Sève, Jonas reconhece, no "Imperativo responsabilidade", que a natureza, ela mesma, não conhece a catástrofe. Conclui dizendo: "Não é o antropocentrismo que ameaça a natureza, mas sua visão curta em relação a ela” (SĖVE, 1990.p. 84). Todavia reconhece a grandeza do pensamento de Jonas, sobretudo em relação à "tentação utópica da tecnologia". Encarar a natureza como objeto de respeito é exatamente impor limites ao poder e à utopia tecnológica. Aqui reside o argumento fundado na prudência e contra a arrogância do saber científico. O pretexto de melhorar a humanidade traz à tona a ambigüidade das relações econômicas pautadas pelos interesses.

A terceira crítica aponta para "o estatuto prescritivo ou impeditivo da ética de responsabilidade”. Sève transforma esta questão numa pergunta capital: "A ética de responsabilidade permite prescrições afirmativas"? Segundo sua visão, essas prescrições são essencialmente negativas, interditivas, pois se baseiam na antecipação, na possibilidade de que a técnica contenha riscos que possam, realmente, colocar em perigo todo o empreendimento humano. Se "a humanidade deve ser preservada”, então é uma ética da autolimitação do poder. Ele percebe duas questões discordantes que são elaboradas em forma de perguntas: "Qual poderá ser a aceitação popular sobre esta ética? Como definir o limite sobre quando é necessário parar"? (SÈVE, 1990, p. 86).

Sobre a primeira questão, afirma que realmente o objetivo da nova ética é marcar e influenciar comportamentos. Lembra, porém, que o próprio Jonas considera difícil provocar "entusiasmo pela moderação", portanto, terá que se contentar com um "entusiasmo negativo, isto é, o temor". Este poderá conter o desejo utópico e escatológico da tecnologia. A segunda questão é um pouco mais difícil e Sève se reporta novamente ao "acaso". Considera o elogio ao acaso uma boa coisa, no entanto pode assegurar sofrimentos insuportáveis. Impedindo intervenções, seria provocar sofrimentos, como no caso de doenças hereditárias, sabendo-se que a ciência teria condições de resolver certos problemas. Conclui dizendo que, nesse caso, "temos boas razões para não deixar o acaso jogar o seu jogo" (idem).

Em contrapartida, consideramos que, neste e em outros casos concretos, a ética de responsabilidade precisa considerar os custos e os benefícios. Impedir ou ordenar requer uma avaliação e esta só pode ser 
tomada após detidas considerações sobre os custos e os benefícios de um procedimento. Nesse sentido, o método da "antecipação pela ameaça, antecipação de um mau real, significa a antecipação de um mal possível, mas realmente possível, é a representação de um mal que não existe ainda, mas que pode acontecer" (HOTTOIS, 1993, p. 109).

Sève questiona a responsabilidade com o recém-nascido que Jonas denomina "arquétipo de toda a responsabilidade". Ele fornece um "contra exemplo", afirmando que o recém-nascido é exatamente o "presente” e, por isso, ele se impõe como uma prescrição afirmativa, como alguém que é necessário "nutrir, cuidar, acalmar” (SÈVE,1990, p. 86).

Se, para Jonas, a criança constitui-se o arquétipo de toda a responsabilidade, à medida que necessita de cuidado, por ser frágil, Robert Spaemann considera:

Esta responsabilidade não se fundamenta nem sobre um princípio, nem sobre uma máxima, mas sim numa percepção. Porque a criança existe, e porque ela precisa de sua mãe, eis aí o que explica o fato de a mãe existir para ela, sem que para isso precise haver intermediação de qualquer princípio que seja. (SPAEMANN, 1996, p. 283).

Spaemann vincula seu conceito na própria "exigência de auto conservação" ao dizer que "o corpo do ser humano necessita da ajuda solidária dos demais”. A nossa dependência comum não decorre do fato de vivermos no mesmo planeta. "Precisamos uns dos outros para nos tornar reais enquanto seres para a liberdade. Sem interpessoalidade não há pessoa” (idem).

Desse debate, Sève conclui: o que o futuro longínquo impõe à minha responsabilidade é, por definição, indeterminado e, por isso, $\mathrm{O}$ princípio da responsabilidade implica numa casuística, no bom sentido da palavra.

Entendemos a angústia de Sève; não obstante, a preocupação com o futuro é possível e depende do cuidado com o presente em relação ao frágil. Para Bochenski, (1961, p. 80) o homem é o "mais frágil de todos os seres"; em Jonas, é a fragilidade do recém-nascido que, por si só, reclama cuidado. Só com o desenvolvimento moral o homem passará de objeto a sujeito da responsabilidade. 
A quarta crítica a Jonas se reporta "a articulação da ética de responsabilidade com a política” que para Seve é o coração da ética da responsabilidade. No nosso entendimento, Jonas tenta superar uma moral cuja ação é determinada pelo agir próximo, entre amigos e inimigos. "Agora a moral de responsabilidade é a primeira cujo inimigo é o coletivo e anônimo”. É uma responsabilidade direcionada a tudo e a todos, mesmo porque a tecnologia é um processo global de expansão. É uma responsabilidade não recíproca, envolvendo cuidados em todas as direções. $\mathrm{O}$ agir coletivo é o seu objeto, e ele se encontra em toda a parte. A tarefa política adquire uma dimensão de cuidado. "Cedo ou tarde, os governos terão que tomar medidas contra a poluição, incentivando pesquisas sobre formas limpas de energia, ainda que isso acarrete renúncias para as quais o capitalismo ainda não está preparado”. Este é um alerta para que se tome consciência dos perigos e ameaças oriundos desse desenvolvimento desenfreado. Essas idéias de Jonas são muito fecundas, mas ele próprio reconhece que a "política é a parte mais fraca do seu sistema tanto do ponto de vista teórico como operatório". Jonas mesmo afirma ter suas próprias idéias e reconhece que talvez sejam impopulares (SÈVE, 1990, p. 87).

Seve (1990, p. 88) não pretende multiplicar as dificuldades, mas levanta a questão:

Como integrar a responsabilidade em direção ao futuro, distante dos parâmetros da decisão? Não exageremos mais sobre a relativa impotência desta ética porque as decisões eventuais de redução dos impactos pertencem mais à autoridade política, outras decisões dependem particularmente dos indivíduos ou de comitês éticos: questões que se referem à manipulação genética por exemplo (decisões nas quais o Estado tem eventualmente também o dever de se envolver).

Finaliza, extraindo três conclusões do pensamento de Jonas: A primeira se refere à "futurologia que pode parecer um pouco catastrófica; mas, no caso, a significação do pessimismo enunciado é específico: o pior não é sempre seguro, mas o que parece possível deve ser evitado a todo o custo". A segunda se refere ao que autoriza e mesmo exige propor os prognósticos mais sombrios: "segundo o princípio da heurística do temor é 
necessário fazer os indiferentes tomarem consciência dos perigos”. Em terceiro, "O princípio responsabilidade" é um livro sobre ética, mas é também um ato ético". Em "A ciência como experiência pessoal”, Jonas afirma: "O trabalho teórico faz parte da práxis prescrita nele e gostaríamos de vê-lo colocado à serviço do próprio imperativo" (idem).

Para ele, "O princípio responsabilidade" possui duas linhas de pensamento muito diferentes:

A primeira está relacionada a exposição dos imperativos da responsabilidade (que me parece muito convincente)". A segunda, que quer fundar os imperativos na metafísica da natureza parece um tanto frágil. Certamente, Jonas não aceitaria a mudança de seu pensamento fora da argumentação metafísica (idem).

No nosso entendimento, Jonas agiu intencionalmente como prémoderno. Foi caminho encontrado para chamar a atenção do niilismo moderno, da onipotência da ciência e esquecimento do homem como valor. É também nesse sentido que deve ser entendida a crítica que faz a Kant e à moral tradicional. Para ele o agir moderno exige novos princípios que garantam a continuidade da existência, sem querer destruí-la. A "antecipação pela ameaça” revela a necessidade de uma ética da renúncia diante do excesso de poder e da "desmesura" da ciência moderna. Consideramos uma escolha coerente, à medida que a responsabilidade com o futuro é diferente da jurídica. Zelar pelo futuro é ser responsável pelo presente e por sua permanente possibilidade de vir-a-ser. Cuidar do presente significa estar zelando pelo futuro não só da vida humana como também da natureza.

Richard Marienstras analisa o pensamento de Jonas no âmbito da política atual. Preocupa-se em encontrar meios ou recentrar a governabilidade em princípios democráticos, de tal forma que a "democratização da decisão ajude a evitar desequilíbrios e abusos de poder”. André Dumas enfoca seu objeto de análise no horizonte político. Incursionaremos inicialmente nas observações de Marienstras.

Marienstras concorda com Jonas em que o espaço de ação se alterou em decorrência dos impactos tecnológicos e que os imperativos da ética tradicional e do dever são insuficientes para o agir, que sofre constantemente choques tecnológicos. 
A noção mesma de responsabilidade reenvia ao indivíduo, no momento em que a organização social e a técnica são de essência coletiva. De sorte que é por assim dizer normal que hajam perdido o controle dos nossos espaços sociais, não tenhamos êxito para ganhar de nossos dispositivos técnicos. Esta constatação nos faz duvidar que a distinção entre o natural e o social seja pertinente e nos faz tomar uma visão mais ampla das coisas (...) nós vivemos num fluxo múltiplo onde reina a relatividade generalizada (MARIENSTRAS. 1994, p. 187).

Reconhece que, doravante, a tarefa do moralista não deve buscar "somente o bem humano, mas também reconhecer um fim em si na natureza”. Chama a atenção de Jonas, afirmando que a questão não está no excesso de antropocentrismo das morais tradicionais, mas em conceber o homem "isolado" da natureza, num cosmos contemplado com absoluta indiferença. Considerar o "fim em sì" da natureza, separado da "ação humana", é reforçar a dicotomia entre "arte e natureza” (idem).

Eu não sei se a ética tem um futuro. A lei, pelo contrário, poderá ter um; a lei, isto é, no seu sentido latino que liga os homens e cria entre eles um espaço policiado. A diferença com a ética, é que a lei assim compreendida pode não ser mais que convenção. $\mathrm{O}$ espaço que ela delimita não é aquele da cidade ou somente aquele da cultura: ela compreende também a natureza (como ela aliás, tem sempre feito), e aquela na sua totalidade definida pelo universo simbólico. (...) o espaço policiado terá que garantir aquilo que foi definido. Podemos certamente sonhar, e dizer que a ameaça da morte genética será o fundamento da nova lei. Isto é duvidoso: é o desequilíbrio interno das sociedades e os conflitos suscitados no seio delas que torna possível a utilização das forças destruidoras que controlamos de maneira tão precária" (idem).

Marienstras insiste sobre a necessidade da retomada da questão da organização social. Nesse âmbito deverá ser discutida a "justiça social e as organizações políticas”, no sentido mais banal e tradicional do termo. Com 
relação às instituições políticas, entende a questão no domínio próprio da política:

Pois se o homem (isto é a coletividade humana) quer decidir seu destino, deve buscar os meios institucionais de fazer conhecer e de aplicar suas decisões, (...) através dos meios mais elementares da ação política e moral. (...) em curto prazo, os poderes políticos e tecnológicos estão usurpados por diversas instâncias detentoras dos meios de ação, de decisões e de conhecimento; em longo prazo, ninguém decide nada, os novos acontecimentos tecno-políticos são decididos ou se decidem eles mesmos por uma força da inércia - pelo efeito totalizador de uma multiplicidade de decisões incoerentes, convergentes, divergentes ou rivais (MARIENSTRAS, 1994, p. 189).

A imoralidade está no fato de pequenos grupos decidirem pela maioria. Portanto, a responsabilidade consiste em desenvolver o hábito de tomar decisões que correspondam ao interesse da comunidade inteira e não somente "da família, da vida, do partido ou do país. O que importa não são as modalidades técnicas, mas como são tomadas as decisões que envolvam a educação e as instituições, para, assim, tornar esta democratização possível, não na perspectiva de afastar o perigo, mas de assumi-lo. Não é contrário à nova ética, mas não crê que vá efetivamente melhorar a situação. Acredita em muito mais:

Tornar-se mestre de seu destino significa precisamente estar a altura de respeitar coletivamente as regras morais (ou a lei) ou de poder colocar em questão a lei que nos governa, mudar a demanda da vontade esclarecida e assumir o risco permanente da decisão, torna-se um imperativo (MARIENSTRAS, p. 190).

É realmente possível promover o estatuto da humanidade inteira? Nem Marienstras, nem Jonas terão a resposta, mas a liberdade de poder dizer não aos imperativos antiéticos é uma prerrogativa e precisa ser sempre promovida. O sentido pedagógico da responsabilidade possui a tarefa de relembrar a moralidade, de relembrar que o futuro está implicado na esfera da decisão, do poder e da liberdade. $\mathrm{O}$ aumento da massa crítica poderá 
despertar a consciência sobre os riscos de determinados empreendimentos tecnológicos. Por isso, a invocação do temor adquire um sentido de proteção e vigilância dos indefesos e frágeis.

A comentar o mesmo artigo, André Dumas escreve: "Enfim um artigo que nos reporta à evidência, pois a moral orienta a ação e a ação tem por tarefa tornar a humanidade vivente” DUMAS, 1974, p. 190). A ética deixa de ser considerada numa perspectiva idealista para tratar da vida real. É um convite para que o homem "não falte com o bem que é comandado pela sua liberdade". Três questões necessitam de destaque.

A primeira se refere à "ruptura" tão fortemente marcada entre a ética tradicional e a exigência de novos imperativos para o mundo tecnológico. Para Dumas, Jonas raciocina com uma só oposição, ou seja, uma ética cujo percurso é de Sófocles a Kant, onde o agente deve amar o próximo e conformar-se com a morte, e onde a solução para a vida encontra-se na sabedoria. Temos, de um lado, um tratamento da vida nas suas relações imediatas, e, de outro, a vida e sua sobrevivência, decidida ou programada em longo prazo.

Dumas pergunta: "Esta oposição é um dado real ou uma brilhante especulação de ficção filosófica”? Mostra ceticismo em relação à escolha desse percurso assim contrastado. Ao invés de trabalhar com a ruptura entre passado e futuro, teria ganhado mais em persuasão se tivesse trabalhado com os três momentos sucessivos, atento aos problemas e discussões da época:

O período antigo e medieval ampara sua cosmologia (no criacionismo bíblico) fornecendo sua providência e sua limitação. O cartesiano e marxista de artificialidade histórica, onde a ciência promete à humanidade uma acumulação indefinida. $\mathrm{O}$ terceiro, não é seguramente um retorno em direção a natureza passada do cosmos, onde descobrimos que nosso espírito não tem à sua disposição mais que um corpo e uma terra onde, portanto passamos do respeito antigo e da conquista moderna para aquela famosa procura da convivência, cara a Illich, do viver com, em lugar de viver sob o constrangimento da técnica (DUMAS, 1994, 191).

A segunda refere-se à renúncia ao antropocentrismo, considerando que a natureza tem um direito próprio. Dumas não nega que haja uma verdade nesta descentralização do indivíduo em detrimento do coletivo e do limite 
do fazer humano em proveito da biosfera. Esta crítica dirigida à técnica é procedente à medida que nos propõe conquistas ilimitadas, que podem pôr em risco todo o empreendimento. Entretanto, pergunta: "Sem antropocentrismo como podemos falar de um mundo? Existirá habitat sem habitantes"? Preocupa-se com a possibilidade de destronar o homem do pedestal científico e tecnológico e colocar em seu lugar um "puritanismo da natureza”, uma vez desaparecido o traço transitório do predador humano. Talvez seria a dessacralização errônea da história, uma reverência absurda em direção à permanência da "condição cósmica" (idem).

No nosso entendimento, não entendeu corretamente a crítica que Jonas faz ao antropocentrismo da ética tradicional. Jonas quer estender a responsabilidade também para o mundo da natureza, pois a continuidade da vida humana no planeta depende da sua preservação. Negar o antropocentrismo seria não estar de acordo com o imperativo da vida, onde ele volta a ocupar seu lugar de honra. Vida e natureza são, para Jonas, interdependentes e, dialeticamente, complementares. A compulsão e a onipotência da técnica podem colocar em perigo a "essência substancial". Jonas não está pensando pura e simplesmente na destruição da humanidade, mas na "morte essencial" que advém da desconstrução e da aleatória reconstrução tecnológica do meio ambiente e do homem, por meio da biotecnologia e engenharia genética. O divórcio entre subjetividade e objetividade tornou o conhecimento alheio à subjetividade humana.

Em terceiro lugar, Dumas conclui, dizendo que o artigo de Jonas termina com um apelo à sabedoria. A crise atômica, ecológica, a "apreensão" que esta situação provocou e provoca deve conduzir a uma consciência progressiva diante da possibilidade "não mais do dilúvio como dizia Luis $\mathrm{XV}$ ”, mas do "deserto". É totalmente favorável às injunções de Jonas, em "considerar as gerações futuras como nosso próximo”. E termina, dizendo:

Novamente aqui a ética se faz política diante de questões tão urgentes. Estamos pressionados entre o hábito e o crescimento dos bens culturais, o medo do desemprego, a concorrência internacional tão insistente e aquela ética global da sobrevivência humana que para o momento é uma piedosa promessa (DUMAS, 1994, p. 192). 


\section{Considerações finais}

O que caracteriza verdadeiramente o novo conceito não é apenas sua orientação para o futuro, diferente do horizonte fechado em que o sujeito pode reparar danos causados ou sofridos. A marca é definitivamente distinta da imputabilidade. Somos responsáveis pelo que fazemos, porque nosso poder fazer pode comprometer a continuidade de tudo e de todos. O imperativo da existência cobra o que vamos realizar, e não o que já realizamos, como acontece no direito civil e penal.

Se existem ameaças advindas do mau uso da tecnologia, nesse caso, quem pode ser mais ameaçada é a vida. O novo imperativo está indissociavelmente implicado a ela, pois esta deve ser objeto de preservação. Está expressa exatamente uma ética da vida. A fragilidade do mundo e dos indivíduos nos torna mais responsáveis, sempre responsáveis de um futuro possível para as gerações futuras.

Não obstante, a singularidade de Jonas reside no sustentáculo ontológico da responsabilidade. É uma posição teórica clara, mas, vista com desconfiança por setores da filosofia moderna. Tal reconstrução está distante das tentativas propugnadas por muitas filosofias utilitaristas e finalistas contemporâneas. Nesse sentido, é considerada, por alguns muito mais uma compreensão intuitiva. Entretanto, para Jonas, é claro que o fundamento da ética do futuro não se encontra na ética enquanto doutrina do fazer, mas na metafísica, enquanto doutrina do ser. Defende o conhecimento científico e metafísico, mas chama atenção para os exageros da ciência e do esquecimento do homem enquanto organismo para a liberdade.

O retorno ao argumento ontológico leibneziano nada mais é que uma forma de repensar o dualismo radical de todo o gnosticismo sem descuidar dos efeitos positivos. Foi o caminho encontrado para fundamentar a ética e superar o dualismo, permitindo salvaguardar a humanidade dos poderes destruidores do homem por meio da técnica e retornar à idéia de homem como guardião do ser, de pastor responsável, e não dominador onipotente. É a pedagogia do "Imperativo responsabilidade", que implica numa radical mudança de postura. Ela não é minha, nem sua, mas do sujeito coletivo da moderna subjetividade.

Para Ricoeur, (1996, p. 233) Jonas afirma: é o "homo faber" e o "homo sapiens" que agora estabelece uma relação simbólica e criativa. "O 
homem dá nome às coisas, relaciona os seres, abre o campo do possível: assim, a liberdade se destaca por distanciar-se da causalidade” A função meramente metabólica do mundo animal, cuja existência mostra a não separação entre forma e matéria, agora é perfeitamente possível pelo homem, à medida que ele confecciona imagens, fruto da liberdade, longe de uma conexão puramente causal. O homem incorpora, nos seus simbolismos, fins e valores. A criatividade é expressão de sentido e liberdade.

Qual a lição a ser tirada dessa interpretação? No instante em que supera o dualismo a que nos referimos anteriormente, Jonas recoloca a vida no seu lugar de honra. O conceito de corpo e mente torna-se obsoleto em função do fenômeno de auto-organização. Entretanto, percebemos que a função do metabolismo merece viver. Jonas ressalta uma inter-relação dialética entre corpo e mente, onde necessidades, valores, fins e, sobretudo, a liberdade, no humano, se revelam "desde o começo da vida".

Para Jonas, o perigo tem que ser enunciado em termos ontológicos. Ricoeur enriquece nossa compreensão.

O perigo tem de ser enunciado em termos ontológicos: a possibilidade do não-ser acompanha como uma sombra a asserção do ser pela vida e faz da vida uma aventura improvável e revogável. Daqui provém a terceira lição que nos conduz ao limiar da ética, mas de uma ética ontologicamente fundamentada: o fenômeno de auto-organização, germe da autotranscendência, permite que se fale de um testemunho que a vida dá a ela mesma. A vida não se prova; ela se arrisca e se atesta. Esse testemunho deve ser oposto à concepção moderna segundo a qual a matéria morta é uma evidência e a vida um enigma. Desde o Renascimento, apenas o não-vivente é considerado cognoscível; o vivente deve, pois, ser-lhe reduzido; nesse sentido, todo o nosso pensamento está atualmente sob o domínio da morte; o idealismo da consciência não é, sob esse ponto de vista, menos mortífero, desde que ele sanciona unicamente a inteligibilidade do nãovivente: é em relação a essa ontologia da morte que se diz que a vida dá testemunho para a vida (RICOEUR, 1996, p. 234). 
Ricoeur conclui sua análise dizendo que a arquitetura do fundamento último do princípio de responsabilidade deveria ser coordenada nos três axiomas distintos:

A vida diz sim à vida. A idéia de humanidade exige ser realizada. $\mathrm{O}$ ser vale mais que o não-ser. $\mathrm{O}$ primeiro axioma representaria a contribuição da filosofia da biologia para a ética; quanto ao segundo, não se poderia ver outra coisa, quer Jonas quer não, além de um descendente do kantismo, que poderia se encarregar, entre outras variantes, de uma ética da argumentação; quanto ao terceiro, o mais fundamental, ele deveria guardar a sua marca propriamente leibneziana, com, além do mais, um acento platônico, na medida em que é o $\mathrm{Bem}$, com o B grande, que envolve ser e dever-ser. O segredo do pensamento de Jonas a ser desvendado parece-me consistir na correspondência tácita entre os três axiomas, correspondência que permite que se entre na filosofia de Jonas a partir de qualquer um dos três. Considerados em conjunto, estes me parecem formar um vasto círculo hermenêutico. A questão seria não evitar o círculo, mas entrar nele corretamente (RICOEUR, 1996, p. 243-44).

Ricoeur refere-se ao "Princípio responsabilidade" como "um grande livro", não apenas em razão da "novidade das idéias" sobre técnica e responsabilidade compreendida como "retenção" e "preservação", mas em razão da "intrepidez de seu empreendimento fundacional e dos enigmas que este nos dá para decifrar” (RICOEUR, 1996, p. 244). 


\section{Referências}

ABEL, O. La responsabilité incertaine. Rev. Esprit., Paris, n. 206, p. 20 - 29, nov. 1994 BOCHENSKI, J. M.. Diretrizes do pensamento filosófico. São Paulo: EPU, 1961.

DUMAS, A. Réponse à Hans Jonas. Revue Esprit, Paris, n. 438, p. 185 -190, set. 1974. GREISCH, J. et alli. Entretien avec Hans Jonas: De la gnose au Principe responsabilité. Revue Esprit, Paris, n. 171, p. 5 - 21, maio 1991, p. 5 - 21.

HEIDEGGER, M. . Ser e tempo. 5. ed. Petrópolis: Vozes, 1997, v. 1.

HOTTOIS, G. Aux fondementes d'une éthique contemporaine. Paris: Vrin, 1993.

JONAS, $\mathrm{H}$. The imperative of responsibility: in search of an athics for the technological age. Translated by Hans Jonas with the collaboration of David Herr, Chicago: University of Chicago Press, 1884.

O princípio responsabilidade: ensaio de uma ética para a civilização tecnológica. Rio de Janeiro, Contraponto: Ed. PUC-Rio, 2006.

- Tecnologia e responsabilità: riflessioni sui nuovi compiti dell'etica. Dalla fede antica all'uomo tecnologico, Bologna: Il Mulino, 1991, (Publicato in: Social Research, 15, primavera de 1973).

. Technologie et responsabilité: Pour une novelle éthique. Revue Esprit, Paris, v. 42, n. 438, p. 163 - 184, set 1974.

. Dalla fede antica all'uomo tecnologico. Bologna: Il Mulino, 1991. 465 p.

Tra il nulla e l'eternità. Ferrara: Gallio Editori, 1992. 109 p.

KANT, E. Fondements de la métaphisique des moeurs. Tras. V. Delbos, Librairie philosophique, Paris: J. Vrin, 1980. 81 p.

MARIENTRAS, R. Réponse à Hans Jonas. Revue Esprit, Paris, n. 438, année 42, p. 185 - 190, septembre 1994.

RICOEUR, P. Ethique et politique. Revue Esprit, Paris, n. 101, p. 1 - 10, mai 1985.

. Le concept de responsabilité: Essai d'analise sémantique. Revue Sprit, Paris, n. 206, p. 28 - 48, nov 1994.

. A região dos filósofos. São Paulo: Edições Loyola, 1996.

Em torno ao político. São Paulo: Loyola, 1995.

SÈVE, B. Hans Jonas et l'ethique de la responsabilité. Revue Esprit, Paris, n. 165, p. 72 - 88, oct de 1990.

SPAEMANN, R. Felicidade e benevolência. São Paulo: Loyola, 1996. 308 p.

E-mail: Izanca@uel.br

Recebido em: Setembro/2010 Aprovado em: Dezembro/2010 